\title{
La pycnodysostose : à propos d'un cas clinique
}

\section{Bléno K, Tréguer A, Valette G, Boisramé-Gastrin S. (UFR d'Odontologie, Brest)}

La pycnodysostose (du grec pycnos $=$ dense; dys= défectueux et osteon $=0 \mathrm{~s}$ ) est une dysplasie osseuse rare (1 cas pour 100000) appelée aussi ostéochondrodysplasie.

L'étiologie est génétique à transmission autosomique récessive avec une prévalence identique dans les deux sexes. Comme pour toutes les maladies à transmission autosomique récessive, la consanguinité augmente le risque; ainsi la pycnodysostose est associée à la consanguinité dans 30\% des cas (Hernandez-Alfaro et al, 2011).

Elle a été décrite pour la première fois par Maroteaux et Lamy en 1962. Elle est également appelée maladie de Toulouse-Lautrec, en référence au célèbre peintre français de la fin du XIX ième siècle (Mujawar et al, 2009).

La pycnodysostose est due à un déficit en cathepsine $\mathrm{K}$, enzyme jouant un rôle primordial dans la résorption osseuse par les ostéoclastes. Elle dégrade les protéines de la matrice osseuse : collagène de type 1, ostéopontine et ostéonectine (Alves Pereira et al, 2008).

Le gène codant pour cette enzyme est localisé au niveau du chromosome 1q21. Ceci se traduit par des os particulièrement denses et fragiles du fait des troubles du remodelage osseux que présentent ces patients.

La pycnodysostose se caractérise par un retard staturo-pondéral, des membres courts et massifs, des extrémités atrophiques (lyse des troisièmes phalanges distales), une absence de fermeture des fontanelles antérieures, des bosses frontales et un élargissement des sutures crâniennes.

Les manifestations maxillo-faciales et buccales de cette maladie sont très nettes: les patients présentent une hypoplasie du maxillaire et de la mandibule avec un angle mandibulaire ouvert et parfois absent, un retard d'éruption des dents définitives, des dents impactées, un encombrement dentaire important. La prévalence de la pathologie carieuse et parodontale est également plus élevée (Roriz Fonteles et al, 2007)

Le cas rapporté est celui d'un patient de 52 ans atteint de pycnodysostose ayant fracturé sa mandibule après plusieurs épisodes infectieux sur ses molaires mandibulaires. La pose de plaques d'ostéosynthèse a permis de réduire ces fractures. Le patient a été pris en charge par la suite au niveau parodontal afin d'assurer un maintien de sa denture résiduelle.

Le diagnostic de pycnodysostose se fait relativement jeune du fait du retard statural. II est parfois réalisé plus tard à la suite de fractures pathologiques réitératives dues à des traumatismes minimes. Ainsi, le diagnostic repose sur des arguments cliniques et radiologiques. Le traitement bucco-dentaire repose sur la prévention de la pathologie carieuse et parodontale afin de limiter au maximum les avulsions, sources potentielles de fractures mandibulaires per opératoires ou d'ostéomyélite post-extractionnelle. La conservation des dents est primordiale car la maladie rend difficile leur remplacement par de la prothèse amovible ou implantaire. Le traitement est souvent symptomatique: réduction des fractures et avulsions dentaires.

La prise en charge de ces patients doit être précoce et est multidisciplinaire.

BLENO Kévin

kevin.bleno@hotmail.fr

This is an Open Access article distributed under the terms of the Creative Commons Attribution License 2.0, which permits unrestricted use, distribution, and reproduction in any medium, provided the original work is properly cited. 